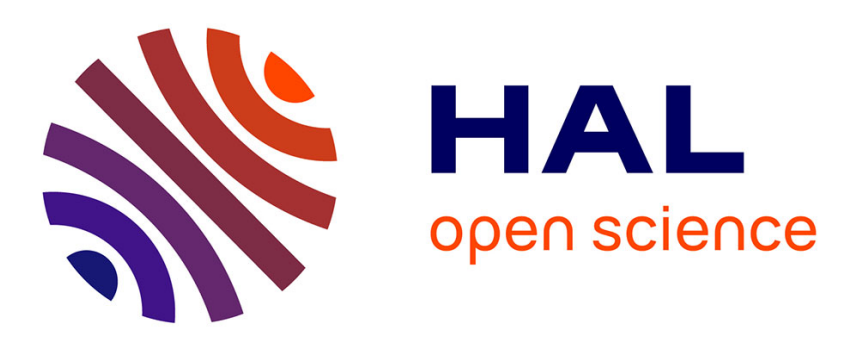

\title{
Broadband noise prediction of a counter rotating open rotor based on LES simulation with phase-lagged assumption
}

\author{
Maxime Fiore, Majd Daroukh, Marc Montagnac
}

\section{- To cite this version:}

Maxime Fiore, Majd Daroukh, Marc Montagnac. Broadband noise prediction of a counter rotating open rotor based on LES simulation with phase-lagged assumption. Journal of Sound and Vibration, 2021, 514, pp.116420. 10.1016/j.jsv.2021.116420 . hal-03339106

\section{HAL Id: hal-03339106 https://hal.science/hal-03339106}

Submitted on 9 Sep 2021

HAL is a multi-disciplinary open access archive for the deposit and dissemination of scientific research documents, whether they are published or not. The documents may come from teaching and research institutions in France or abroad, or from public or private research centers.
L'archive ouverte pluridisciplinaire HAL, est destinée au dépôt et à la diffusion de documents scientifiques de niveau recherche, publiés ou non, émanant des établissements d'enseignement et de recherche français ou étrangers, des laboratoires publics ou privés. 


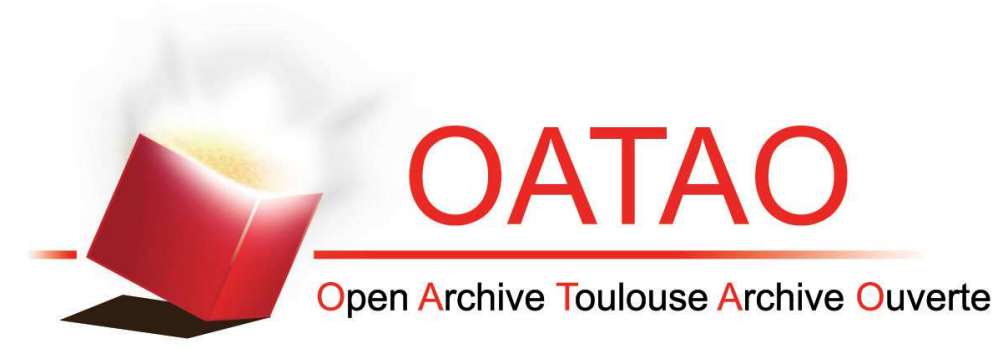

\section{Open Archive Toulouse Archive Ouverte (OATAO)}

OATAO is an open access repository that collects the work of some Toulouse researchers and makes it freely available over the web where possible.

This is an author's version published in: https://oatao.univ-toulouse.fr/28248

Official URL: https://doi.org/10.1016/j.jsv.2021.116420

\section{To cite this version :}

Fiore, Maxime and Daroukh, Majd and Montagnac, Marc Broadband noise prediction of a counter rotating open rotor based on LES simulation with phase-lagged assumption. (2021) Journal of Sound and Vibration. 116420. ISSN 0022460X

Any correspondence concerning this service should be sent to the repository administrator: tech-oatao@listes-diff.inp-toulouse.fr 


\title{
Broadband noise prediction of a counter rotating open rotor based on LES simulation with phase-lagged assumption (draft)
}

\author{
M. Fiore ${ }^{\mathrm{a}, *}$, M. Daroukh ${ }^{\mathrm{b}}$, M. Montagnac ${ }^{\mathrm{c}}$ \\ ${ }^{a}$ ISAE-Supaero, Dpt. of Aerodynamics, Energetics and Propulsion, Toulouse, France \\ ${ }^{\mathrm{b}}$ DAAA, ONERA, University Paris Saclay, Châtillon, France \\ c CERFACS, Computational Fluid Dynamics team, Toulouse, France
}

Counter-rotating open rotor Broadband noise prediction Ffowcs Williams-Hawkings analogy

Large-Eddy simulation

Phase-lagged assumption

POD data storage

\begin{abstract}
A B S T R A C T
This paper presents the broadband noise analysis of a Counter Rotating Open Rotor (CROR) configuration. The numerical study is based on a hybrid approach: a Large Eddy Simulation (LES) code solves the near-flow field of the CROR configuration and the near-to-far-field propagation is then predicted by a Ffowcs Williams-Hawkings analogy either based on a solid or porous formulation. The LES solver uses a phase-lagged assumption with a proper orthogonal decomposition for the data storage. The numerical approach is validated against wind tunnel experimental data of a CROR configuration (AI-PX7) at three different operating points focused on the broadband noise. The analysis of the numerical simulations shows the predominant effect of the rear rotor suction side on the radiated broadband noise with an increasing contribution with span location. This source is related to the impingement of front rotor wakes and the development of leading edge vortices that induce large pressure fluctuations close to the leading edge on the suction side.
\end{abstract}

\section{Introduction}

Counter Rotating Open Rotor (CROR) designs are currently investigated to power the next short- and middle-range civil aircraft generation based on the fuel efficiency benefits compared to conventional turbofan engines [1]. These configurations face noise challenges due to the new sources of noise [2] and no damping of noise by a duct as in turbofan [3]. The noise produced by a CROR comes from many sources but three main mechanisms can be identified: (1) the front and rear rotor self-noise corresponding to the volume displacement and steady loading of the rotor blades [4]; (2) the wake-vortex interaction noise related to the unsteady loading on the rear rotor blades caused by the impingement of the front rotor wakes and vortices; (3) the potential-field interaction noise [5] characterized by the unsteady lift force on the blades due to the potential field of the opposite rotor or even other fixed elements like wing, pylon or fuselage [6].

The noise spectrum of a CROR configuration consists of both tonal and broadband contributions. The tones mostly come from periodic interactions and are emitted at discrete frequencies corresponding to combinations of the Blade Passing Frequencies (BPF) [5]. Within the past decades, the tonal noise has been significantly decreased in CROR configuration by reducing the rear rotor diameter to avoid tip vortex interaction noise, designing swept rotor blades with appropriate blade numbers to minimize interaction tones [7] and using pylon blowing technology [8]. As a consequence, in modern CROR configurations, broadband noise significantly contributes to the overall noise level [7]. Broadband noise is emitted across a broad frequency spectrum and is mainly related to turbulence effects: the passage of the turbulent boundary layer over the trailing edge on the surface of each blade; the

\footnotetext{
* Corresponding author.

E-mail address: maxime.fiore@isae-supaero.fr (M. Fiore).
} 


\section{Nomenclature}

\section{Latin letters}

\begin{tabular}{|c|c|}
\hline$c$ & speed of sound $\left[\mathrm{m} \mathrm{s}^{-1}\right]$ \\
\hline $\mathrm{C}_{x}$ & midspan axial chord-length [m] \\
\hline $\mathrm{D}_{F} / \mathrm{D}_{R}$ & front/rear rotor diameter $[\mathrm{m}]$ \\
\hline$f$ & frequency $[\mathrm{Hz}]$ \\
\hline $\mathrm{Hi}$ & shape factor $[-]$ \\
\hline $\mathrm{R}$ & radius to the microphones $[\mathrm{m}]$ \\
\hline$p$ & pressure $\left[\mathrm{kg} \mathrm{m}^{-1} \mathrm{~s}^{-1}\right]$ \\
\hline$T$ & temperature $[\mathrm{K}]$ \\
\hline$t$ & time $[\mathrm{s}]$ \\
\hline S & sphere surface $\left[\mathrm{m}^{2}\right]$ \\
\hline Ma & Mach number $[-]$ \\
\hline $\operatorname{Re}_{C_{x}}$ & $\begin{array}{l}\text { Reynolds number based on axial chord } u C_{x} / v[-] \\
\text { velocity }\left[\mathrm{m} \mathrm{s}^{-1}\right]\end{array}$ \\
\hline$(x, y, z)$ & Cartesian coordinates $[\mathrm{m}]$ \\
\hline
\end{tabular}

\section{Greek letters}

$\kappa$

$\rho$

$\phi$

$\omega$

Abbreviations

$\begin{array}{ll}\text { AP, CB, SL } & \text { approach, cutback, sideline } \\ \text { BOB } & \text { Broadband noise of Open rotor Blades } \\ \text { BPF } & \text { Blade Passing Frequency } \\ \text { FW-H } & \text { Ffowcs Williams-Hawkings } \\ \text { CROR } & \text { Counter Rotating Open Rotor } \\ \text { POD } & \text { Proper Orthogonal Decomposition } \\ \text { PSD } & \text { Power Spectral Density } \\ \text { PWL } & \text { PoWer Level } \\ \text { LES } & \text { Large-Eddy Simulation } \\ \text { (U)-RANS } & \text { (Unsteady) Reynolds Averaged Navier Stokes } \\ \text { F/R } & \text { Front/Rear rotor } \\ \text { WALE } & \text { Wall-Adapting Local Eddy-viscosity }\end{array}$

artificial viscosity $\left[\mathrm{kg} \mathrm{m}^{-1} \mathrm{~s}^{-1}\right]$

density $\left[\mathrm{kg} \mathrm{m}^{-3}\right]$

polar angle [deg]

rotational speed [ $\mathrm{rad} \mathrm{s}^{-1}$ ]

\section{Subscripts and superscripts}

$\begin{array}{ll}\infty & \text { upstream conditions } \\ \text { ref } & \text { reference quantity } \\ \text { tot } & \text { total quantity } \\ 5^{+} & \text {non-dimensional wall distance } \\ . & \text { fluctuating quantity }\end{array}$

impingement of turbulent wakes from an upstream pylon, fuselage boundary layer, atmospheric turbulence on the front and rear rotor blades [6].

Analytical models have been developed to predict the different sources of broadband noise. Roger and Moreau [9] provide a review of analytical models to deal with the broadband noise generated by thin airfoils related to turbulence-interaction noise, trailing edge noise and vortex-shedding noise. More recently, Moreau and Roger [10] described analytical models used to deal with tonal and broadband noise generation of CROR configurations.

In recent years, the prediction of the noise generated by CROR configurations has been widely performed using hybrid approaches: a computational fluid dynamics solver computes the near-flow field and then an acoustic analogy is used to obtain the noise radiated in the far-field region. This process has been applied using Unsteady Reynolds Averaged Navier-Stokes (URANS) 
Table 1

Characteristics of the experimental setup with the different operating points: approach (AP), cutback (CB) and sideline (SL)

\begin{tabular}{llll}
\hline Cascade details & \multicolumn{3}{l}{ Nominal conditions } \\
\hline Front rotor blades & 11 & $\begin{array}{l}\text { Inc. angle } \\
{[\mathrm{deg}]}\end{array}$ & 0 \\
Rear rotor blades & 9 & $p_{\text {tot, } \infty}[\mathrm{Pa}]$ & 101,179 \\
Hub-to-tip ratio & 0.35 & $T_{\text {tot, } \infty}[\mathrm{K}]$ & 311.5 \\
Rear rotor cropping & 10 & Rot. speed & $512.4(\mathrm{AP})$ \\
$\left(\mathrm{D}_{F}-\mathrm{D}_{R}\right) / \mathrm{D}_{F}[\%]$ & & $\omega\left[\mathrm{rad} \mathrm{s}^{-1}\right]$ & $650.8(\mathrm{CB})$ \\
$\mathrm{C}_{\mathrm{x}} / \mathrm{D}_{\mathrm{F}}$ & & & $738.2(\mathrm{SL})$ \\
$\mathrm{L}_{F-R} / \mathrm{D}_{F}$ & 0.11 & $\mathrm{Re}_{\mathrm{C}_{\mathrm{x}}}$ & $6.6 \times 10^{5}$ \\
\hline
\end{tabular}

simulations coupled with a Ffowcs Williams-Hawkings (FW-H) analogy for the prediction of tonal interaction noise [11-13] and by Spakovszky and Peters [14] to predict individual contributions to the interaction tone noise using full-wheel URANS simulations and a frequency domain approach based on Goldstein's formulation of the acoustic analogy. The Large-Eddy Simulation (LES) approach [15] resolves the large energetic scales of turbulence and only the small scales are modeled making the approach suitable to capture both the tonal and broadband noise contributions. The full-wheel LES of a realistic CROR configuration is still challenging due to the high mesh density necessary to accurately resolve acoustic pressure disturbances. For the purpose of reducing the computational cost with acceptable hypothesis, a phase-lagged assumption approach is used in this study. This method assumes that the full 360-degree flow at a given time step can be reconstructed using a unique pair of front and rear rotor blades at different prescribed time steps (corresponding to the different relative positions of the front rotor blades compared to the rear rotor blades). This method allows to reduce the simulation domain to a single passage per row, as proposed by Erdos and Alzner [16]. The main difficulty with the phase-lagged approach lies in the necessary storage of the flow variables at each time step over a full passage of the opposite rotor blade at the phase-lagged interfaces. It corresponds to the storage of the flow variables at the interface between the two counter rotating rows and on lateral azimuthal conditions. For the meshes and time steps in practical turbomachinery simulations, a direct storage represents a significant cost. The data storage cost is reduced by using a data compression method, the Proper Orthogonal Decomposition (POD) [17]. LES includes multiple unknown frequencies, for example non-deterministic small scales structures in a turbulent wake, for which the characteristic time that needs to be used is unknown. POD compression is more able to capture these phenomena compared to the Fourier Series Decomposition proposed by He [18,19]. The POD compression method has been implemented in the phase-lagged approach of the elsA code by Mouret et al. [20,21]. This approach is used to perform the LES of a CROR configuration (AI-PX7) tested experimentally to characterize the broadband noise generated at three different operating points.

The purpose of this paper is to assess the capability of LES with phase-lagged assumption and POD data storage to capture the broadband noise generated by CROR configurations and analyze the sources of broadband noise based on the numerical simulations performed. The far-field noise signature is obtained by coupling the LES with a FW-H analogy for solid and permeable surfaces.

The paper is organized as follows: Section 2 introduces the configuration, experimental measurements and the numerical setup; the comparison of the numerical simulations with experimental data and an analytical model available for the three different operating points is presented in Section 3; the analysis of the broadband noise mechanisms is finally detailed in Section 4.

\section{Configuration and numerical methods}

The CROR configuration used for the study is the Airbus Clean Sky generic Open Rotor configuration AI-PX7 $11 \times 9$ at scale 1/7. The CROR AI-PX7 is an isolated CROR representative of a rear fuselage pylon-mounted pusher configuration. The front rotor is composed of 11 blades and the rear one of 9 blades. The axial distance between the front (F) and rear (R) rotor is set to $\mathrm{L}_{F-R} / \mathrm{D}_{F}=0.22$ where $\mathrm{D}_{F}=0.61 \mathrm{~m}$ is the front rotor diameter. The rear rotor is cropped in order to avoid the front rotor tip vortices to impact the rear rotor [22] (10\% cropping compared to the front rotor). The front and rear rotors are designed with positive sweeping on the upper part of the blade. The main geometrical features are gathered in Table 1 (left column). More details about the CROR AI-PX7 design are described in Negulescu [23].

Within the European JTI CleanSky project Smart Fixed Wing Aircraft program, acoustic measurements of the 1/7 scale model have been performed in the DNW-LLF open jet wind tunnel (Marknesse, Netherland). The nominal conditions used during the experiments for the three different operating points are gathered in Table 1 (right column). The acoustic instrumentation shown in Fig. 1 is composed of 43 microphones installed on an airfoil-shaped frame moving inside the flow. The airfoil-shaped frame describes a portion of circle with radius $\mathrm{R}=11 \mathrm{D}_{F}$ from the forward polar arc region at polar angle $\phi=25$ deg to aft polar arc region at $\phi=160 \mathrm{deg}$ where the origin is set at the mid-position between front and rear rotors. More details about the experiments are provided in Paquet et al. [24].

The simulation domain shown in Fig. 2 is composed of two sub-domains: one sub-domain extending from the inlet set upstream of the configuration to the mid-position between the front rotor trailing edge and rear rotor leading edge; a second sub-domain extending from this same position to the outlet set downstream of the rear rotor. 1/11 of the full azimuthal domain is considered for the front domain corresponding to the simulation of one of the 11 front rotor blades rotating at the rotational speed $\omega$ and $1 / 9$ of 


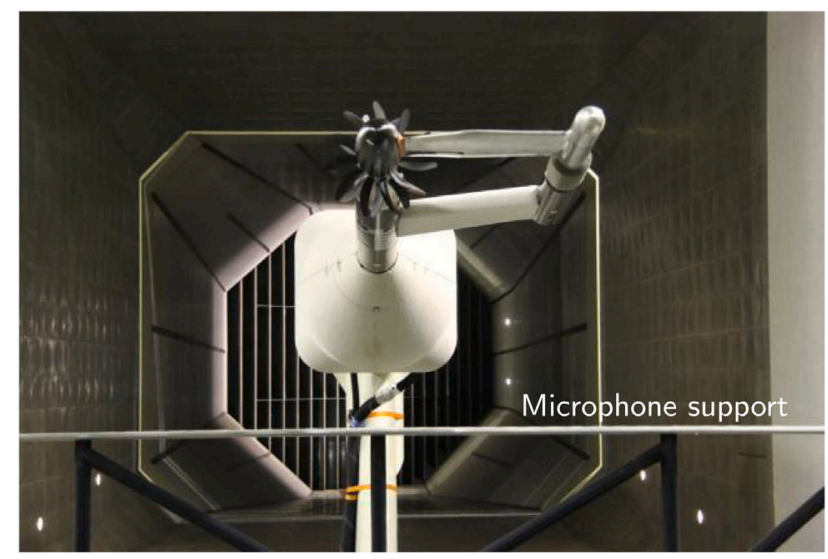

Fig. 1. AIPX-7 model in the DNW-LLF open jet wind tunnel and microphone traverse.

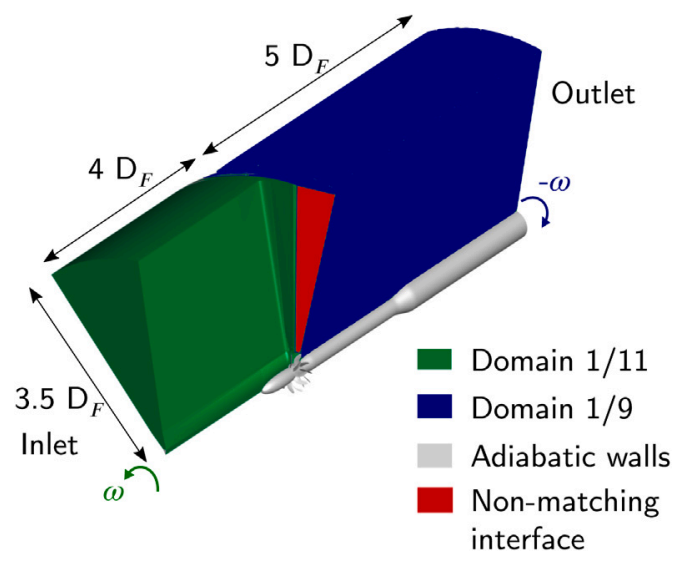

Fig. 2. Simulation domain.

the full azimuthal domain is computed for the rear domain corresponding to the simulation of one of the 9 rear rotor blades at the rotational speed $-\omega$. The simulation domain extends $4 \mathrm{D}_{F}$ upstream of the front of the configuration in the streamwise direction. The outlet is set at the rear of the nacelle which is $5 \mathrm{D}_{F}$ long. The radius of the simulation domain is $3.5 \mathrm{D}_{F}$. At the full non-matching interface between the front and rear sub-domain and on the lateral surfaces, phase-lagged conditions are applied.

The mesh is based on an $\mathrm{O}-4 \mathrm{H}$ topology for the two rotor rows. The first off-wall point is set to $\Delta y / \mathrm{C}_{x}=4 \times 10^{-5}\left(\Delta y^{+} \leq 1\right)$ where $C_{x}$ is the midspan axial chord. According to the literature [25-28], the near-wall region should be resolved in LES with $50 \leq \Delta x^{+} \leq 80 ; \Delta y^{+} \leq 1 ; 15 \leq \Delta z^{+} \leq 25$. These criteria are challenging to fulfill for the present configuration with a high Reynolds number and large dimensions. Therefore, the mesh has been coarsened in the $\mathrm{x}$ and $\mathrm{z}$ direction to reach a mean spanwise coordinate of $\Delta z^{+} \simeq 60$ and mean streamwise coordinate of $\Delta x^{+} \simeq 100$. Fig. 3 shows the midspan grid dimensions at the front and rear rotor blade walls for the SL operating point confirming the targeted value for the first off-wall points. The mesh is composed of $350 \times 10^{6}$ cells.

The simulations are performed using the ONERA elsA software [29] solving the compressible Navier-Stokes equations over multi-block structured grids and used in previous studies on CROR configurations [30-32]. A second-order centered scheme with a low Jameson artificial viscosity [33] $\left(\kappa_{\text {jam. }}^{4}=0.002\right)$ is used for the convective discretization. The subgrid-scale model is the Wall-Adapting Local Eddy-viscosity (WALE) [34]. The time integration is performed using a Dual Time Stepping with a CrankNicholson scheme (second-order accurate) in combination with an implicit pseudo-time stepping for the inner loops [35]. The time step is set to $\Delta t^{+}=\Delta t \mathrm{u}_{\infty} / \mathrm{C}_{x}=1 \times 10^{-3}$ corresponding to 11,880 iterations per full rotation. The POD compression method relies on successive singular value decompositions of the matrix composed of the conservative quantities at the phase-lagged interfaces stored dynamically during the simulation. At a given time step, the POD modes from the singular value decomposition are sorted in decreasing energy magnitudes and only the first POD modes are conserved to perform the data compression. For the present study, the 30 most energetic modes are conserved based on a previous study [20]. The compressed data stored at the given time step is then imposed later (after a phase-lagged period of time) to the opposite boundary for azimuthal conditions and on the opposed interface 


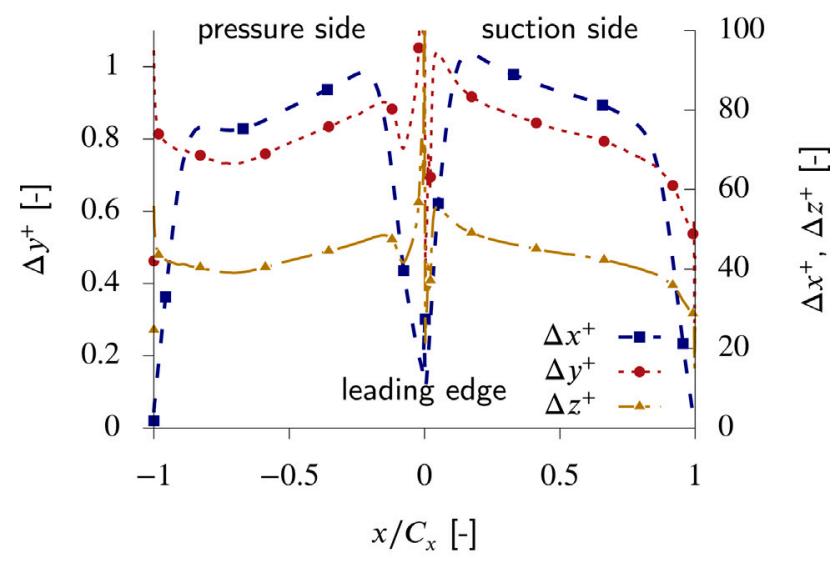

(a)

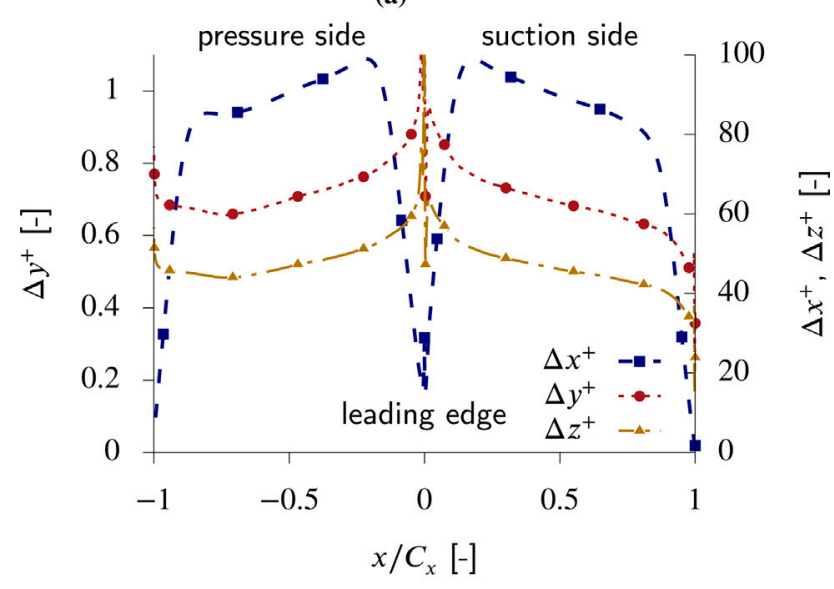

(b)

Fig. 3. Grid dimensions at the front (a) and rear rotor walls (b) at midspan for the SL operating point.

for the non-matching interface. The storage of the flow variables on the phase-lagged interfaces for one full rotation corresponds to a storage requirement of 68.2 Giga bytes in POD compared to 226.6 Giga bytes for a direct storage.

The near-to-far-field propagation is carried out with the ONERA code KIM [36] which solves the FW-H equation [37] in the time domain and considering a uniform freestream propagation medium. Both solid and porous surface formulations of the FW- $\mathrm{H}$ equation are used in the study. Fig. 4 shows the different steps of the hybrid method used from the near-field simulation to the spectral content of far-field microphones. For the porous approach, the quantities ( $\rho, \rho \mathrm{u}, \rho \mathrm{v}, \rho \mathrm{w}, \mathrm{p})$ are stored during the simulation on a surface surrounding the configuration. The FW-H porous formulation in KIM contains additional surface integral terms based on the flux of the Lighthill tensor through the control surface that can represent an approximation of the missing volume integral terms and makes possible to more properly handle the passage of wake vortical structures downstream of the rotor rows [38,39]. For the solid approach, the sources correspond to the wall pressure fluctuations on the front and rear rotor blades. The full 360-degree porous and solid wallblade surfaces are reconstructed at each time step using the phase-lagged method: for a given iteration (ite), the adjacent sectors flow field correspond to the flow simulated at ite +120 , ite +240 , etc. for the upstream rotor while for the rear rotor, the information is based on the flow at downward iterations: ite-120, ite-240, etc. An example of the phase-lagged reconstruction of the axial Mach number $\left(\mathrm{Ma}_{x}\right)$ at $80 \%$ of the front rotor radius for the three different operating points (AP, CB, SL) is shown in Fig. 5. Based on the numerical parameters, mesh and time intervals used in the data storage of FW-H surfaces, the hybrid method is able to resolve phenomena in a bandwidth $[115 \mathrm{~Hz}, 4-7 \mathrm{KHz}]$ in the full-scale geometry $1 / 1$ used for the comparison against experiments. 2970 snapshots of the 360-degree porous and solid surfaces are given as an input to the FW-H solver corresponding to three full rotations of the configuration. The solver propagates the input signal to the far-field providing the pressure fluctuation signal on each microphone. The spectral content of each microphone signal is obtained by computing the Power Spectral Density (PSD) using Welch's overlapped segment averaging estimator, Hamming windowing and 30\% window overlap. 


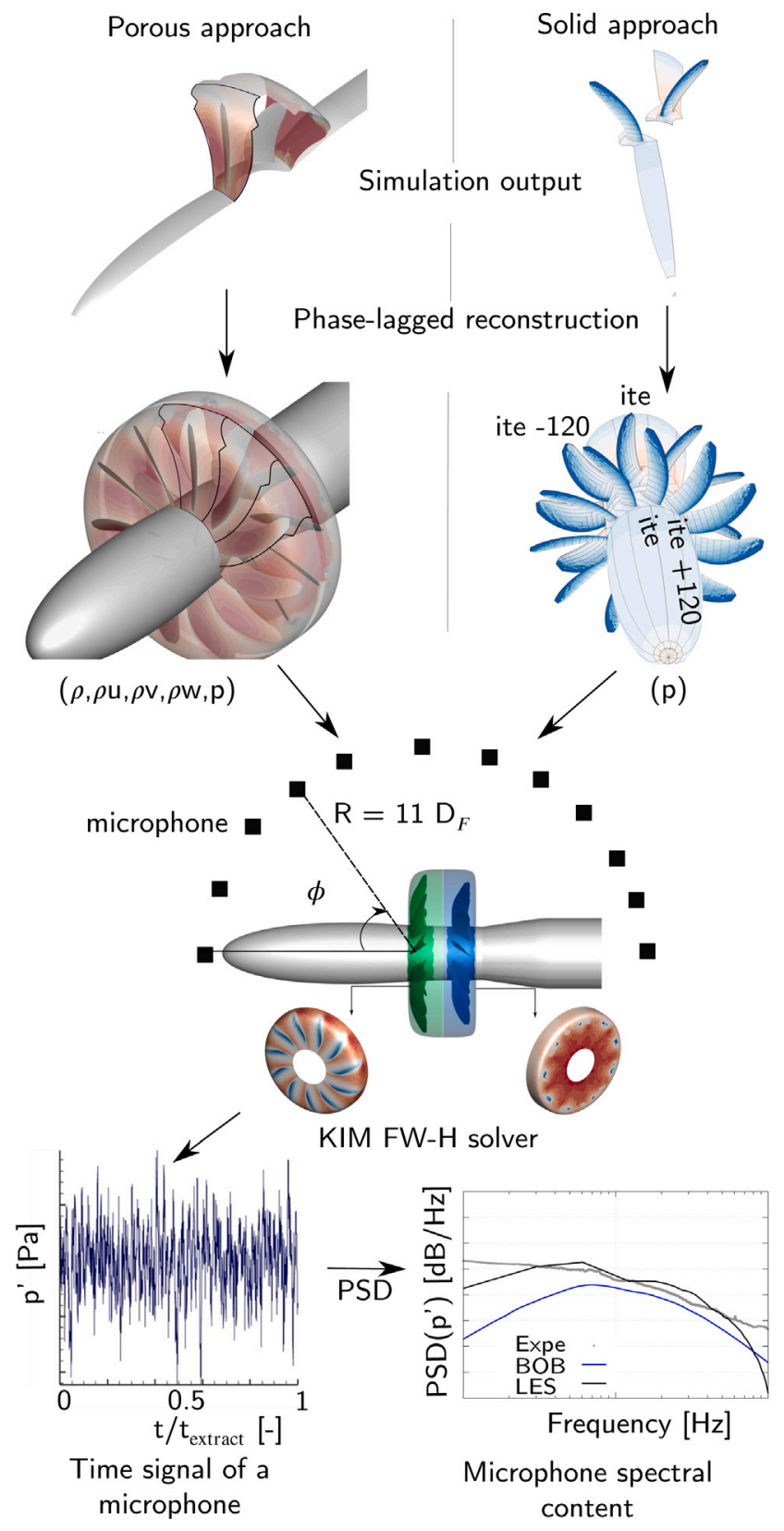

Fig. 4. Description of the hybrid approach steps.

\section{Comparison against experimental data}

The validation of the numerical simulations against experimental data is based on the porous approach. In addition, the results are compared with the ones of the Broadband noise of Open rotor Blades (BOB) analytical model jointly developed by the Airbus Noise Technology Centre (University of Southampton) and Airbus Company. This code predicts the main sources of CROR broadband noise based on Amiet's flat plate airfoil theory: the trailing edge noise is based on the diffraction of the boundary layer turbulent vortices by the trailing edge [40,41]; the wake-vortex interaction noise is based on the interaction of velocity gusts on a profile [4244]. The wake profiles of the front rotor at the three operating points based on RANS simulations are used to define the velocity gusts impacting the rear rotor profile. Details about the analytical code and validation against experimental data are provided in Nodé-Langlois et al. [45]. 


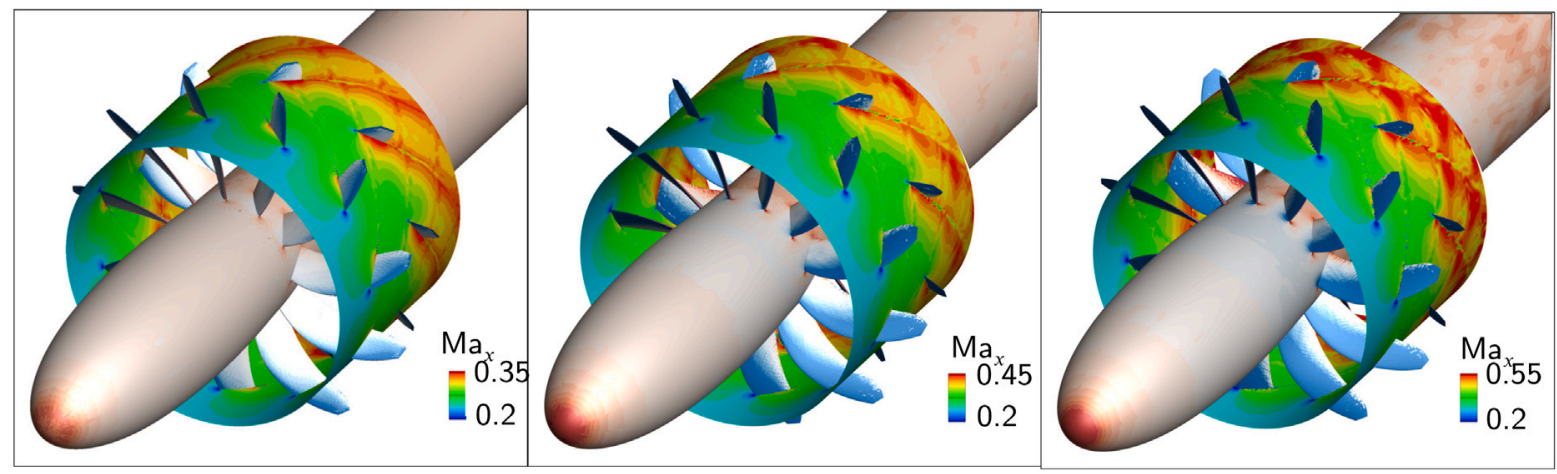

Fig. 5. View of the flow at $80 \%$ span for the three operating points based on phase-lagged reconstruction: AP (left), CB (center), SL (right).

The PoWer Level (PWL) is computed by integration of the acoustic intensity over the portion of sphere S surrounding the CROR between $\phi=25 \mathrm{deg}$ and $\phi=160 \mathrm{deg}$ based on the microphone spectra using the following formula:

$$
\begin{aligned}
& \operatorname{PWL}(f)=10 \log \left(\int_{S} \frac{p^{\prime}(f, R, \phi)^{2}}{\rho_{\infty} c_{\infty}} F\left(\phi, M_{\infty}\right) d S\right)-120 \\
& \text { with } F\left(\phi, M_{\infty}\right)=\frac{\left(1-M_{\infty}^{2}\right)^{2} \cdot \sqrt{1-M_{\infty}^{2} \sin ^{2}(\phi)}}{\left(\sqrt{1-M_{\infty}^{2} \sin ^{2}(\phi)}-M_{\infty} \cos (\phi)\right)^{2}}
\end{aligned}
$$

where $p^{\prime}$ is the pressure fluctuation at the considered frequency, $M_{\infty}, \rho_{\infty}$ and $c_{\infty}$ are the freestream Mach number, density and speed of sound. Fig. 6 shows the PWL spectrum for the different operating points. In the figures that follow, a top-right box indicates if it corresponds to a polar integration, an isolated microphone or an isolated frequency. The mean level of the broadband noise in the range $[100 \mathrm{~Hz}, 10,000 \mathrm{~Hz}$ ] corresponds to $42 \mathrm{~dB}$ at $\mathrm{AP}, 52 \mathrm{~dB}$ at $\mathrm{CB}$ and $58 \mathrm{~dB}$ at SL. The largest noise radiated occurs in the range $[500 \mathrm{~Hz}, 2000 \mathrm{~Hz}]$. At AP where the broadband noise is most likely to dominate, two main differences can be exhibited between the LES/BOB analytical code and the experiments: low levels tones are observed in the experiments which are not predicted by the LES or BOB. During the experiments, interaction processes between the shear layer of the open test section and the CROR configuration at AP were observed and may explain these tones obtained in the experiments. Also, the radiated sound power is overpredicted by $\mathrm{BOB}$ and the LES with a maximum discrepancy of $5 \mathrm{~dB}$ in the range [500 Hz, $5000 \mathrm{~Hz}$ ] for the LES compared to the experiments. This discrepancy may be explained by some difficulties in the experimental measurement and post-processing at AP, the noise radiated by the configuration being relatively low due to the small size of the CROR (1/7 of the full-scale) and the low rotational speed for this operating point. At higher rotational speed (CB), the numerical simulation agrees well with the experiments in the frequency range $[300 \mathrm{~Hz}, 7000 \mathrm{~Hz}$ ] with a maximum discrepancy of around $2 \mathrm{~dB}$. At SL, the simulation also agrees well with the experiments in the frequency range $[700 \mathrm{~Hz}, 4000 \mathrm{~Hz}$ ] with a maximum discrepancy of $3 \mathrm{~dB}$. The analytical model underpredicts the radiated noise compared to the experiments with a maximum discrepancy of $5 \mathrm{~dB}$ in the frequency range [500 Hz, 5000 Hz] at CB and SL but the trend is correctly recovered. Fig. 7 shows the PSD of isolated microphones located in the forward polar arc region $(\phi=51$ deg), at the normal to the main axis $(\phi=96 \mathrm{deg})$ and in the aft polar arc region $(\phi=119 \mathrm{deg})$ of the configuration for the CB operating point. The agreement for integrated spectra (PWL) is also observed locally for microphones set on the front, center and rear polar arc regions of the configuration. The same local agreement is also observed at the SL operating point. The directivity of the broadband noise can also be assessed by focusing on particular frequencies. For each microphone, the amplitude at given frequencies (500, 2000, 4000 and $8000 \mathrm{~Hz}$ ) is stored to give access to their polar distribution. The result of this process is shown in Figs. 8 and 9 for the CB operating point. At the frequencies 500, 2000 and $4000 \mathrm{~Hz}$, the agreement is good at the different polar angles with a maximum local discrepancy around $3 \mathrm{~dB}$. At a higher frequency $(8000 \mathrm{~Hz})$, the radiated sound is underpredicted by the simulation at all polar angles. This behavior is attributed to the mesh cut-off estimated in the present simulations around $7000 \mathrm{~Hz}$ inducing the break down in radiated energy for higher frequencies. Similarly to the experiments, the LES does not exhibit a noise reduction around the normal of the configuration $(\phi=90 \mathrm{deg})$ contrary to the analytical model BOB. According to the authors, the reduced noise predicted by the analytical model may be induced by the isolated blade assumption of the model (i.e. no interaction and diffraction between the blades are taken into account). At all the isolated frequencies presented, a directivity pattern emerges with higher noise levels radiated towards the forward polar arc region between $\phi=20 \mathrm{deg}$ and $\phi=50 \mathrm{deg}$.

\section{Analysis of the broadband noise sources}

This section is devoted to characterize the near-field acoustic field responsible for the far-field noise results previously described in Section 3. Fig. 10 shows an instantaneous time derivative of pressure in the meridional plane and in a radial slice at $80 \%$ of the front blade height for the CB operating point. In the meridional plane, the pressure waves associated with the tip vortices released by the front and rear rotors are highlighted. Also, the pressure waves generated in the wake of the front and rear rotors can be identified in the radial cut. Fig. 11 shows the PWL obtained from the solid FW-H approach considering separately the front, rear and 


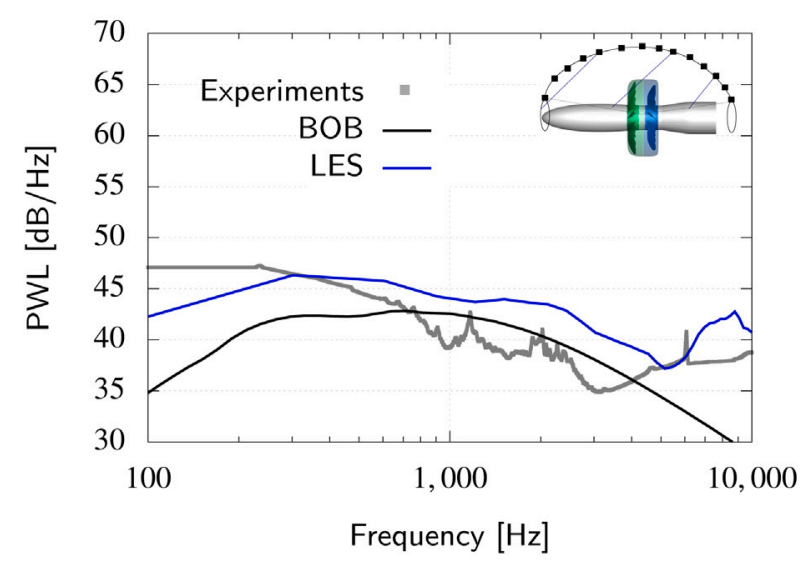

(a)

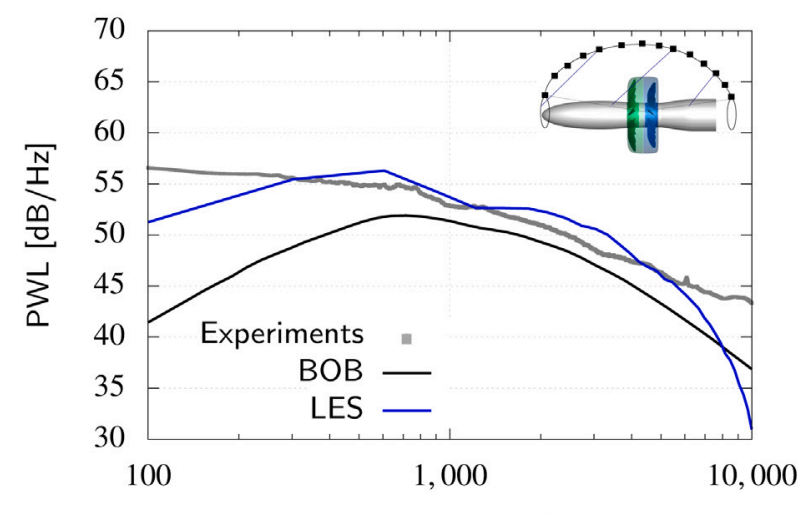

Frequency $[\mathrm{Hz}]$

(b)

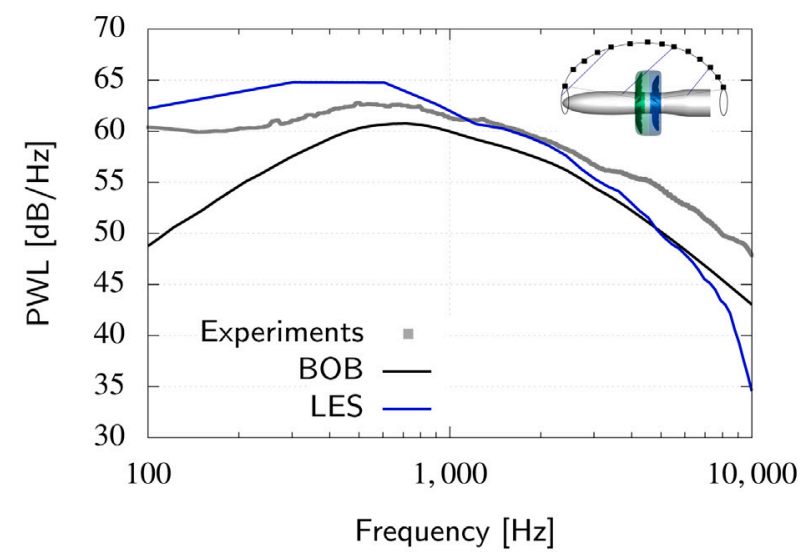

(c)

Fig. 6. PWL comparison at the AP (a), CB (b) and SL (c) operating points.

front-rear contributions at the CB operating point. The PWL obtained using the porous approach is also added in the comparison. The rear rotor is the dominant source of broadband noise compared to the front rotor as expected. Compared to the porous approach, the solid approach for the front and rear rotors displays the same evolution of the PWL with frequency except that the level is 2-5 dB lower. The solid approach accounts for the monopole sources related to the volume displacement of fluid during the blades motion and may be significant compared to dipole sources at cutback and sideline since the tip Mach numbers are around 0.5-0.6. 


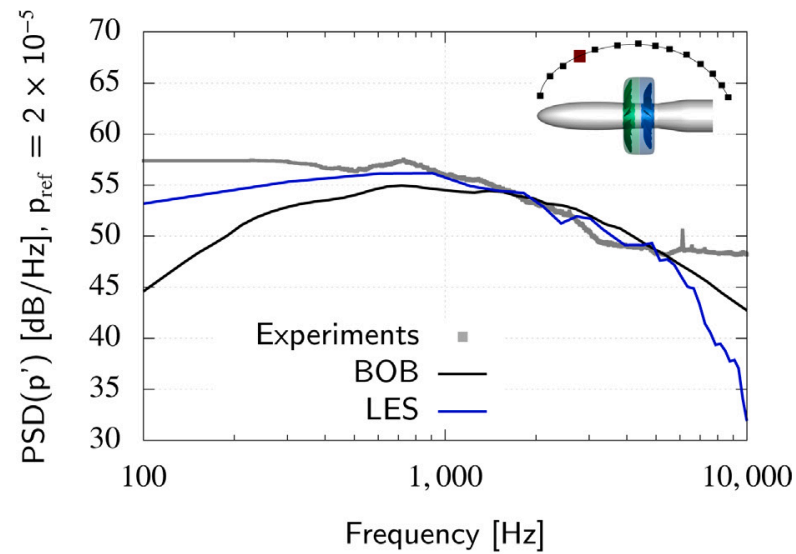

(a)

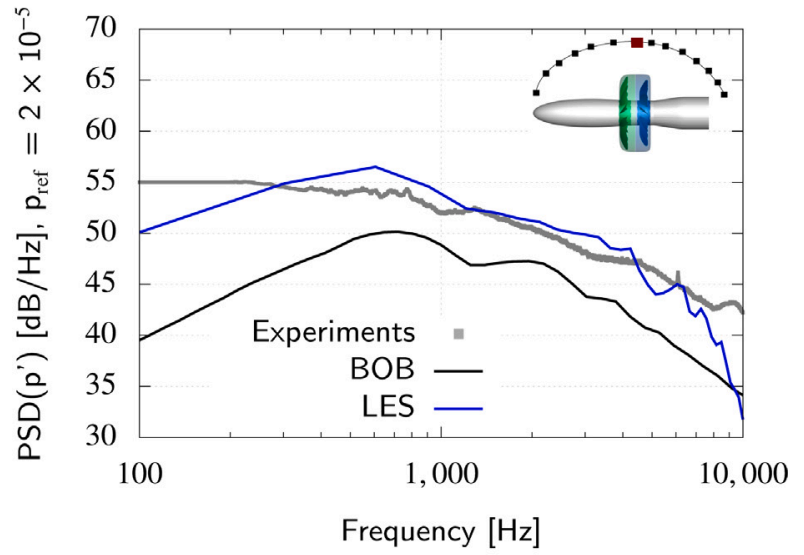

(b)

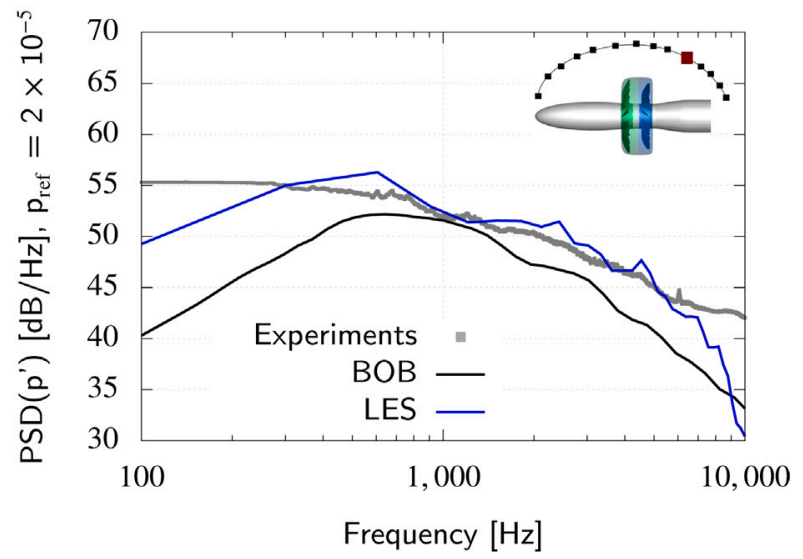

(c)

Fig. 7. PSD of the microphone at a polar angle $\phi=51 \mathrm{deg}(\mathrm{a}), \phi=96 \mathrm{deg}$ (b) and $\phi=119 \mathrm{deg}$ (c) at CB.

The solid approach does not contain the quadrupole noise sources (especially the sound generated in the volume due to turbulent effects) compared to the porous surface which may explain the lower radiated noise by the solid approach. Based on the works of Williams and Hawkings [37], the contribution of quadrupole sources should be relatively small since the tip relative Mach number of the rear rotor is around 0.5 for the CB case while quadrupole sources are generally significant compared to dipole sources at tip Mach number above 0.9. However, Colin et al. [12] also observed higher tonal noise levels comparing porous and solid FW-H 


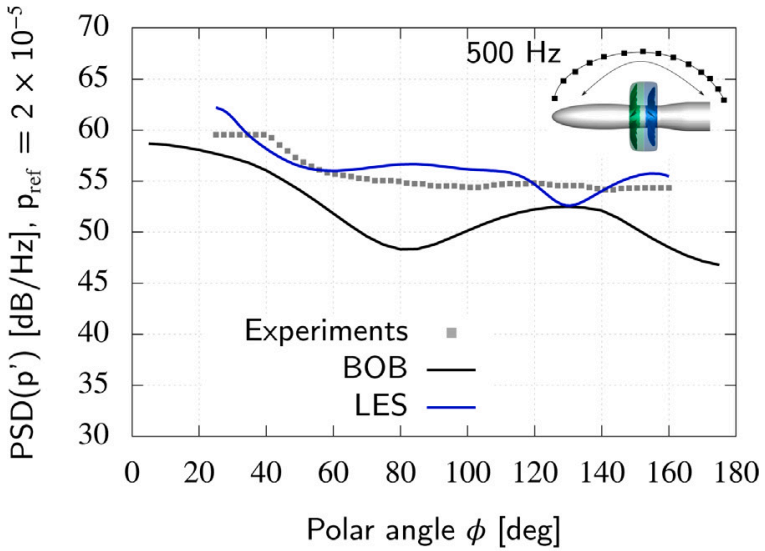

(a)

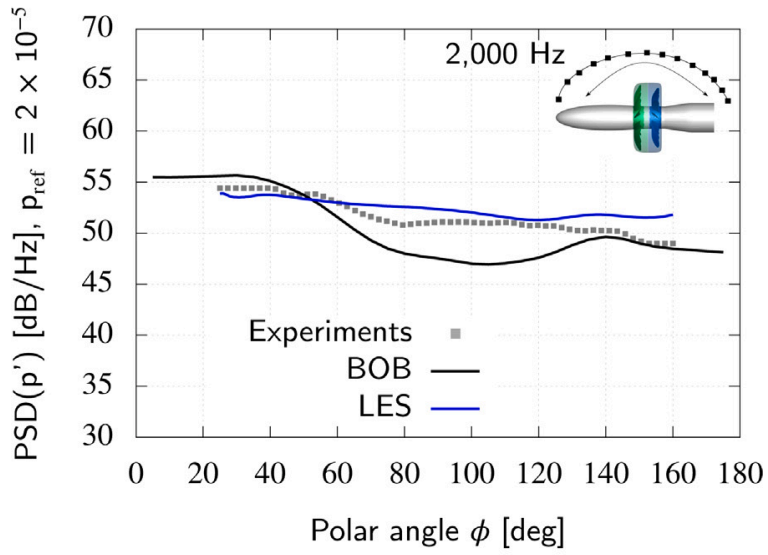

(b)

Fig. 8. Acoustic level at the fixed frequencies $f=500 \mathrm{~Hz}$ (a) and $f=2000 \mathrm{~Hz}$ (b) for different polar angles at the CB operating point.

approaches based on URANS simulations of a CROR at the same inlet Mach number and attributed the difference to the quadrupole terms. On the other side, some noise may be artificially generated by the wakes crossing the porous surface downstream of the two rows despite additional treatments are implemented in KIM.

In order to further investigate the sources on the rear rotor, a chord-frequency diagram showing the pressure PSD over the pressure (left) and suction (right) sides is given in Fig. 12 at different radius corresponding to 10\% (bottom), 50\% (center), 90\% (top) of the blade height for the $\mathrm{CB}$ operating point. As already observed on the far-field noise spectra, the acoustic sources are more energetic in the frequency range $[500 \mathrm{~Hz}, 2000 \mathrm{~Hz}]$. The contribution of the pressure side is relatively weak compared to the one of the suction side. The diffraction argument would suggest that the magnitude of the pressure fluctuations on the pressure and suction surfaces of the airfoil to be equal. This asymmetry can be related to the wake structures from the front rotor predominantly impacting the suction side of the rear rotor due to the geometrical incidence of the blade profile (see Fig. 5). Fig. 13 shows an instantaneous iso Q-criterion at $Q=10^{6}$ colored by the streamwise vorticity of the flow around the rear rotor suction side. In addition, the shape factor Hi defined as the ratio between the displacement and momentum thickness around the rear rotor suction side based on a temporally averaged flow field solution for the CB operating point is provided. Since the front and rear rotors are swept, a leading edge vortex develops on the suction side similarly to the one occurring on swept wings. Based on the shape factor values close to 1.3 on the upper part of the blade downstream of the leading edge vortex, the leading edge vortex, in addition to the upstream freestream turbulence from the front rotor wakes, promote the transition of the suction side boundary layer initially laminar close to the leading edge towards a turbulent state. The leading edge vortex induces large pressure fluctuations close to the rear rotor leading edge in addition to the impingement of the front rotor wake and corresponds to the location of the main sources observed in the chord-frequency diagram between $\mathrm{x} / \mathrm{C}_{x}=0$ and 0.1 . The intensity of the noise sources increases with the span location and can be related to the leading edge vortex that progressively extends over a larger part of the chord as the radius increases before merging with the tip vortex. 


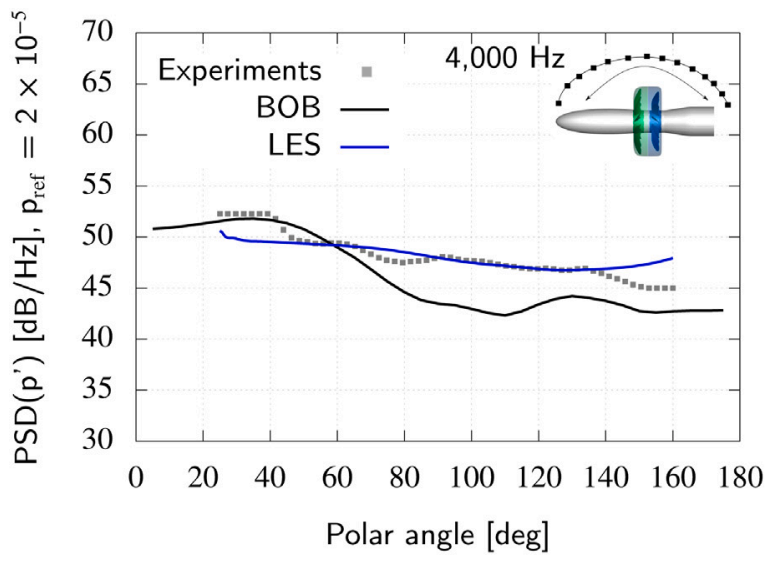

(a)

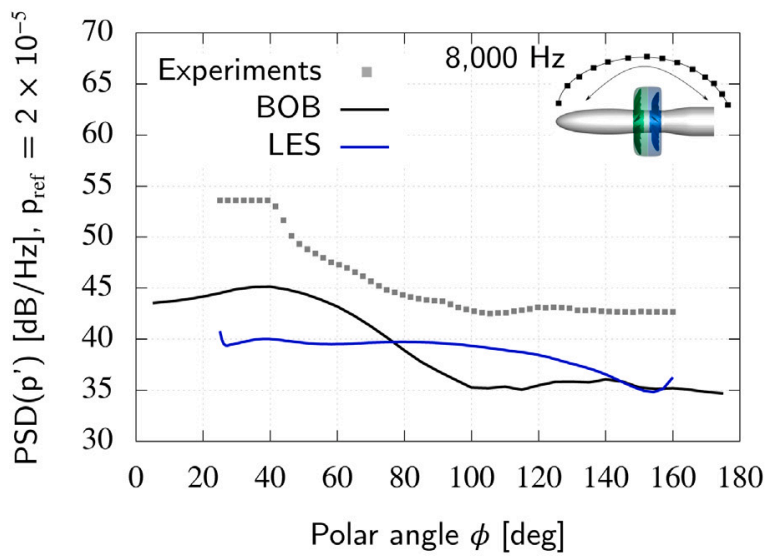

(b)

Fig. 9. Acoustic level at the fixed frequencies $f=4000 \mathrm{~Hz}$ (a) and $f=8000 \mathrm{~Hz}$ (b) for different polar angles at the CB operating point.

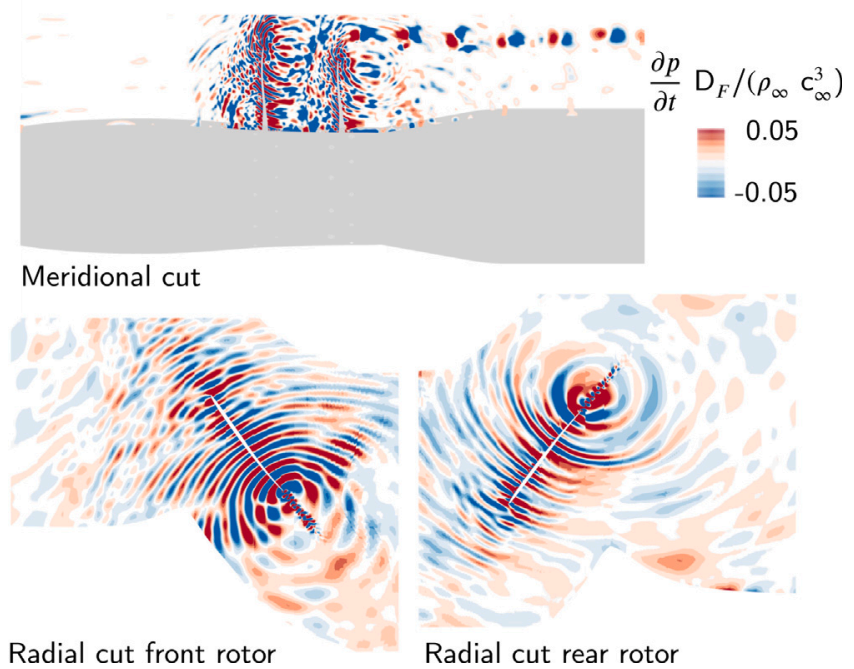

Fig. 10. Snapshot of pressure time-derivative field from LES at the CB operating point. 


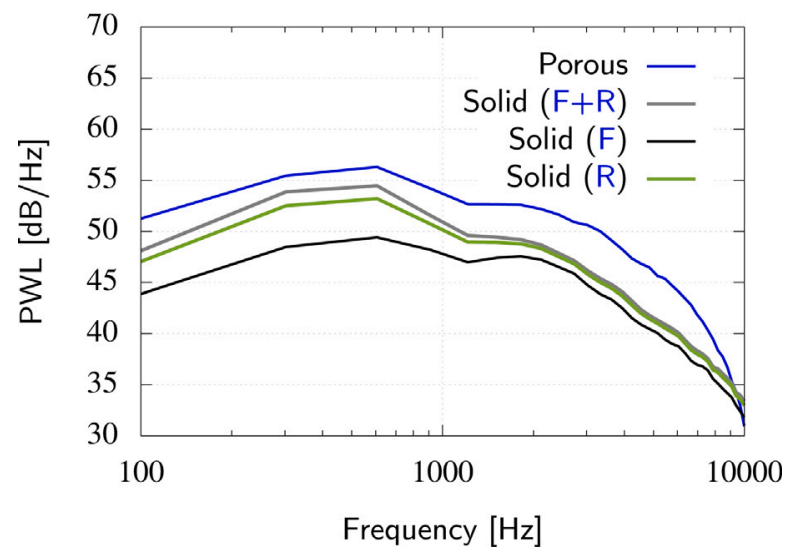

Fig. 11. PWL comparison for the porous and solid approaches (front and rear rotors) at the CB operating point.

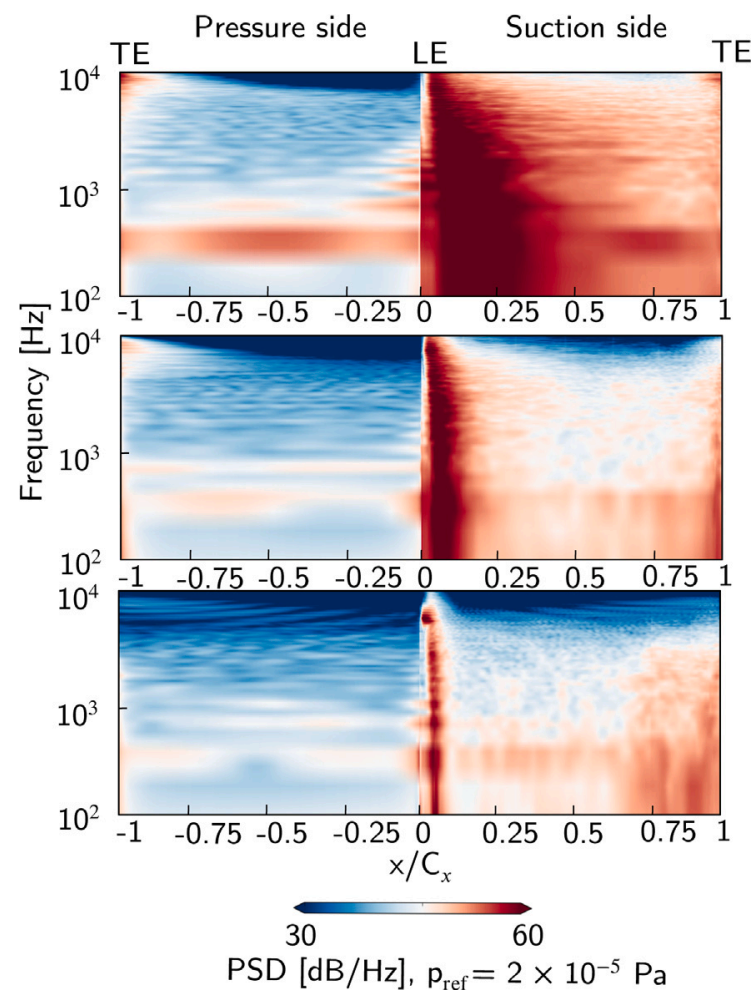

Fig. 12. Chord-frequency diagram of the pressure PSD around the rear blade pressure (left) and suction side (right) at three different radius corresponding to $10 \%$ (bottom), $50 \%$ (center), $90 \%$ (top) of the blade height for the CB operating point.

\section{Conclusion}

The hybrid approach based on the LES solver with phase-lagged assumption and far field propagation using the Ffowcs WilliamsHawkings analogy shows a good agreement with the experimental data of the isolated CROR AI-PX7 configuration. The numerical approach shows a discrepancy lower than $3 \mathrm{~dB}$ for the power level at cutback and sideline operating points in the frequency range $[700 \mathrm{~Hz}, 4000 \mathrm{~Hz}]$.

For the different operating points, the highest level of broadband noise is radiated in the range [500 Hz, $2000 \mathrm{~Hz}]$. In terms of directivity, the broadband noise is predominantly radiated towards the forward polar arc region between 20 deg and 50 deg.

The comparison between the porous and solid FW-H approaches confirms that the main sources of broadband noise are mainly located on the rear rotor blades. More precisely, the analysis of the rear rotor blade surface pressure fluctuations shows a predominant effect of the suction side compared to the pressure side especially close to the leading edge with an extent corresponding 


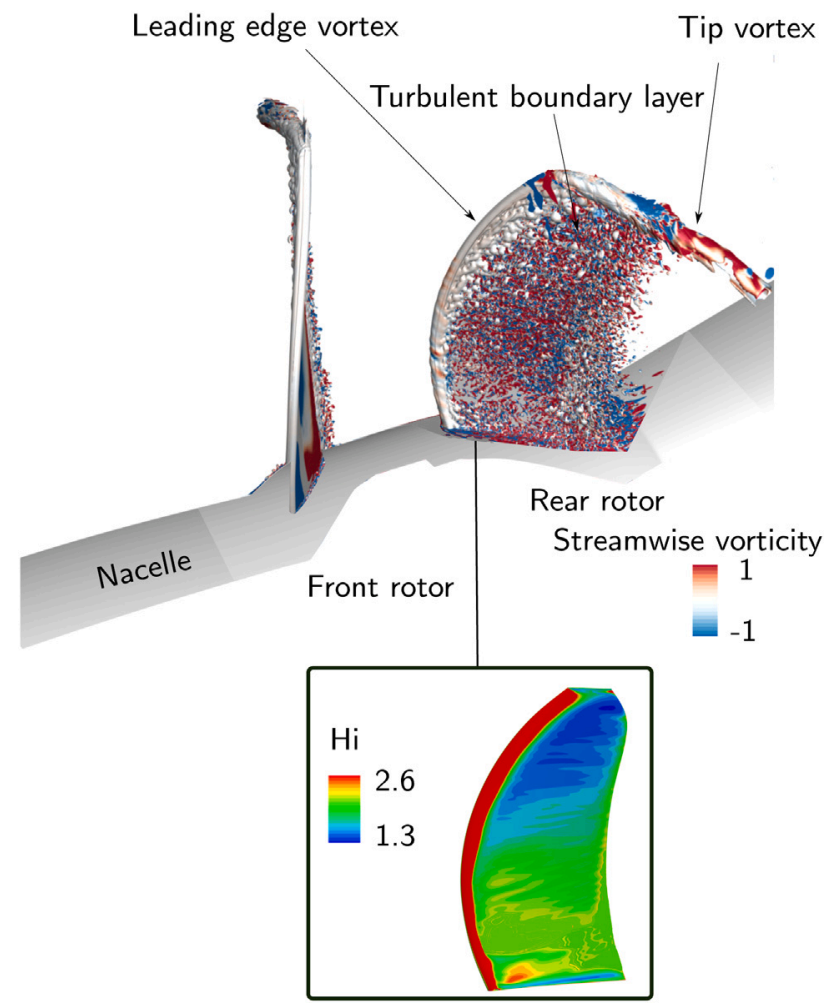

Fig. 13. Instantaneous iso $\mathrm{Q}$-criterion at $\mathrm{Q}=10^{6}$ colored by the streamwise vorticity of the flow around the rear rotor suction side for the $\mathrm{CB}$ operating point, shape factor $\mathrm{Hi}$ around the rear rotor suction side. (For interpretation of the references to color in this figure legend, the reader is referred to the web version of this article.)

to around $10 \%$ of the axial chord. This contribution becomes stronger when moving towards the tip of the rear rotor. This noise source distribution can be related to the wake from the front rotor impacting predominantly the suction side and the leading vortex inducing large pressure fluctuations close to the leading edge on the rear rotor suction side.

\section{CRediT authorship contribution statement}

M. Fiore: Conceptualization, Formal analysis, Investigation, Writing - review \& editing. M. Daroukh: Validation, Formal analysis, Investigation. M. Montagnac: Methodology, Software, Data curation, Resources, Supervision.

\section{Declaration of competing interest}

The authors declare that they have no known competing financial interests or personal relationships that could have appeared to influence the work reported in this paper.

\section{Acknowledgments}

The authors are thankful to Airbus for technical support, the European Commission for having funded this research project within the SCONE project (Grant agreement number 755543), to ONERA for licensing Cerfacs to use the codes elsA and KIM (with the help of Thomas Le Garrec for its use). Numerical post-processing has been performed using the python-based library Antares. This work was performed using HPC resources from GENCI, France - [CCRT-CINES-IDRIS] (Grant 2020-[A0062A06074]). Experimental data were obtained within the European research JTI CleanSky 1 project Smart Fixed Wing Aircraft program (SFWA).

\section{Appendix A. Supplementary data}

Supplementary material related to this article can be found online at https://doi.org/10.1016/j.jsv.2021.116420. 


\section{References}

[1] D.E. Van Zante, Progress in open rotor research: A U.S. perspective, in: Proceedings of the ASME Turbo Expo, ASME, Montreal, Quebec, Canada, 2015, pp. 120-131, http://dx.doi.org/10.1115/GT2015-42203.

[2] E. Hendricks, M. Tong, Performance and weight estimates for an advanced open rotor engine, in: 48th AIAA/ASME/SAE/ASEE Joint Propulsion Conference \& Exhibit, AIAA, Atlanta, Georgia, 2012, http://dx.doi.org/10.2514/6.2012-3911.

[3] R. Schnell, J. Yin, C. Voss, E. Nicke, Assessment and optimization of the aerodynamic and acoustic characteristics of a counter rotating open rotor, J. Turbomach. 134 (6) (2012) 061016, http://dx.doi.org/10.1115/1.4006285.

[4] A. Sharma, H.N. Chen, Prediction of aerodynamic tonal noise from open rotors, J. Sound Vib. 332 (16) (2013) 3832-3845, http://dx.doi.org/10.1016/j. jsv.2013.02.027.

[5] D.B. Hanson, Noise of counter-rotation propellers, J. Aircr. 22 (7) (1985) 609-621, http://dx.doi.org/10.2514/3.45173.

[6] N. Peake, A.B. Parry, Modern challenges facing turbomachinery aeroacoustics, Annu. Rev. Fluid Mech. 44 (3) (2012) 227-248, http://dx.doi.org/10.1146/ annurev-fluid-120710-101231.

[7] A.B. Parry, M. Kingan, B.J. Tester, Relative importance of open rotor tone and broadband noise sources, in: 17th AIAA/CEAS Aeroacoustics Conference 2011 (32nd AIAA Aeroacoustics Conference), AIAA, Portland, Oregon, 2011, pp. 158-169, http://dx.doi.org/10.2514/6.2011-2763.

[8] J. Ricouard, E. Julliard, M. Omaïs, V. Regnier, A.B. Parry, S. Baralon, Installation effects on contra-rotating open rotor noise, in: 16th AIAA/CEAS Aeroacoustics Conference (31st AIAA Aeroacoustics Conference), 2010, http://dx.doi.org/10.2514/6.2010-3795.

[9] M. Roger, S. Moreau, Extensions and limitations of analytical airfoil broadband noise models, Int. J. Aeroacoustics 9 (3) (2010) 273-305, http: //dx.doi.org/10.1260/1475-472x.9.3.273.

[10] S. Moreau, M. Roger, Advanced noise modeling for future propulsion systems, Int. J. Aeroacoustics (ISSN: 20484003) 17 (6-8) (2018) 576-599, http://dx.doi.org/10.1177/1475472X18789005.

[11] Y. Colin, A. Carazo, B. Caruelle, T. Node-Langlois, A. Parry, Computational strategy for predicting CROR noise at low-speed part I: review of the numerical methods, in: 18th AIAA/CEAS Aeroacoustics Conference, AIAA, Colorado Springs, 2012, http://dx.doi.org/10.2514/6.2012-2221.

[12] Y. Colin, F. Blanc, B. Caruelle, F. Barrois, N. Djordjevic, Computational strategy for predicting CROR noise at low-speed part II: investigation of the noise sources computation with the chorochronic method, in: 18th AIAA/CEAS Aeroacoustics Conference, AIAA, Colorado Springs, 2012, http: //dx.doi.org/10.2514/6.2012-2222.

[13] Y. Colin, B. Caruelle, A.B. Parry, Computational strategy for predicting CROR noise at low-speed part III: investigation of noise radiation with the ffowcs-williams hawkings analogy, in: 18th AIAA/CEAS Aeroacoustics Conference, AIAA, Colorado Springs, 2012, http://dx.doi.org/10.2514/6.2012-2223.

[14] A. Peters, Z.S. Spakovszky, Rotor interaction noise in counter-rotating propfan propulsion systems, J. Turbomach. 134 (1) (2011) 011002, http: //dx.doi.org/10.1115/1.4003223.

[15] P. Sagaut, Large Eddy Simulation for Incompressible Flows: An Introduction, Springer Science \& Business Media, 2006, p. 558, http://dx.doi.org/10.1007/ b137536.

[16] J. Erdos, E. Alzner, Computation of unsteady transonic flows through rotating and stationary cascades. 1: Method of analysis, Technical report, National Aeronautics and Space Administration, 1977.

[17] G. Berkooz, The proper orthogonal decomposition in the analysis of turbulent flows, Annu. Rev. Fluid Mech. 25 (1) (2002) 539-575, http://dx.doi.org/ 10.1146/annurev.fluid.25.1.539.

[18] L. He, Method of simulating unsteady turbomachinery flows with multiple perturbations, AIAA J. 30 (11) (1992) 2730-2735, http://dx.doi.org/10.2514/ 3.11291 .

[19] L. He, Fourier Methods for turbomachinery applications, Prog. Aerosp. Sci. 46 (8) (2010) 329-341, http://dx.doi.org/10.1016/j.paerosci.2010.04.001.

[20] G. Mouret, N. Gourdain, L. Castillon, Adaptation of phase-lagged boundary conditions to large eddy simulation in turbomachinery configurations, J. Turbomach. 138 (4) (2015) 041003, http://dx.doi.org/10.1115/1.4032044.

[21] G. Mouret, Adaptation of phase-lagged boundary conditions to large-eddy simulation in turbomachinery configurations, (Ph.D. thesis), INP Toulouse, 2016.

[22] M. Roger, C. Schram, S. Moreau, On vortex-airfoil interaction noise including span-end effects, with application to open-rotor aeroacoustics, J. Sound Vib. (2014) http://dx.doi.org/10.1016/j.jsv.2013.09.012.

[23] C.A. Negulescu, Airbus AI-PX7 CROR design features and aerodynamics, SAE Int. J. Aerosp. 6 (2) (2013) 626-642, http://dx.doi.org/10.4271/2013-01-2245.

[24] C. Paquet, E. Julliard, N. Genoulaz, J. Ricouard, P. Spiegel, Z08: Low-speed aero-acoustic experimental characterization of open rotor installation on aircraft, in: 20th AIAA/CEAS Aeroacoustics Conference, 2014, http://dx.doi.org/10.2514/6.2014-2747.

[25] U. Piomelli, Wall-layer models for large-eddy simulations, Prog. Aerosp. Sci. 44 (6) (2008) 437-446, http://dx.doi.org/10.1016/j.paerosci.2008.06.001.

[26] N. Gourdain, F. Sicot, F. Duchaine, L. Gicquel, Large eddy simulation of flows in industrial compressors: a path from 2015 to 2035 , Phil. Trans. R. Soc. A 372 (2022) (2014) 20130323, http://dx.doi.org/10.1098/rsta.2013.0323.

[27] R. Pichler, Y. Zhao, R.D. Sandberg, V. Michelassi, R. Pacciani, M. Marconcini, A. Arnone, LES And RANS analysis of the end-wall flow in a linear LPT cascade with variable inlet conditions, part I: Flow and secondary vorticity fields, in: ASME Turbo Expo 2018: Turbomachinery Technical Conference and Exposition, ASME, Oslo, Norway, 2018, http://dx.doi.org/10.1115/GT2018-76450.

[28] P.G. Tucker, Computation of unsteady turbomachinery flows: Part 2-LES and hybrids, Prog. Aerosp. Sci. 47 (7) (2011) 546-569, http://dx.doi.org/10. 1016/j.paerosci.2011.07.002.

[29] L. Cambier, S. Heib, S. Plot, The Onera elsA CFD software: input from research and feedback from industry, Mech. Ind. 14 (3) (2013) 159-174, http://dx.doi.org/10.1051/meca/2013056.

[30] A. Giauque, B. Ortun, B. Rodriguez, B. Caruelle, Numerical error analysis with application to transonic propeller aeroacoustics, Comput. \& Fluids 69 (3) (2012) 20-34, http://dx.doi.org/10.1016/j.compfluid.2012.07.022.

[31] G. Delattre, F. Falissard, Influence of torque ratio on counter-rotating open-rotor interaction noise, AIAA J. 53 (9) (2015) 2726-2738, http://dx.doi.org/ 10.2514/1.J053797.

[32] G. Delattre, F. Falissard, L. Vion, L. Jacquin, Open rotor interaction noise reduction through front rotor wake modification, Int. J. Aeroacoustics 15 (2) (2016) 207-227, http://dx.doi.org/10.1177/1475472X16643461.

[33] A. Jameson, W. Schmidt, E. Turkel, Numerical solutions of the Euler equations by finite volume methods using Runge-Kutta time-stepping schemes, AIAA Pap. 6 (2) (1981) 1259, http://dx.doi.org/10.2514/6.1981-1259.

[34] F. Nicoud, F. Ducros, Subgrid-scale stress modelling based on the square of the velocity gradient tensor, Flow Turbul. Combust. 62 (3) (1999) 183-200, http://dx.doi.org/10.1023/A:1009995426001.

[35] C. Marmignon, V. Couaillier, B. Courbet, Solution strategies for integration of semi-discretized flow equations in elsA and CEDRE, AerospaceLab J. 2 (1) (2011) 1-11.

[36] J. Prieur, G. Rahier, Aeroacoustic integral methods, formulation and efficient numerical implementation, Aerosp. Sci. Technol. 5 (7) (2001) 457-468, http://dx.doi.org/10.1016/S1270-9638(01)01123-3.

[37] J.E. Williams, D.L. Hawkings, Sound generation by turbulence and surfaces in arbitrary motion, Roy. Soc. London-Philosophical Trans. Ser. A 264 (1151) (1969) 321-343, http://dx.doi.org/10.1098/rsta.1969.0031. 
[38] G. Rahier, J. Prieur, F. Vuillot, N. Lupoglazoff, A. Biancherin, Investigation of integral surface formulations for acoustic post-processing of unsteady aerodynamic jet simulations, Aerosp. Sci. Technol. 8 (6) (2004) 453-467, http://dx.doi.org/10.1016/j.ast.2004.04.005.

[39] G. Rahier, M. Huet, J. Prieur, Additional terms for the use of Ffowcs Williams and Hawkings surface integrals in turbulent flows, Comput. \& Fluids 120 (11) (2015) 158-172, http://dx.doi.org/10.1016/j.compfluid.2015.07.014.

[40] R.K. Amiet, Noise due to turbulent flow past a trailing edge, J. Sound Vib. 47 (3) (1976) 387-393, http://dx.doi.org/10.1016/0022-460X(76)90948-2.

[41] R.K. Amiet, Effect of the incident surface pressure field on noise due to turbulent flow past a trailing edge, J. Sound Vib. 57 (2) (1978) 305-316, http://dx.doi.org/10.1016/0022-460X(78)90588-6.

[42] R.K. Amiet, Compressibility effects in unsteady thin-airfoil theory, AIAA J. 12 (2) (1974) 252-264, http://dx.doi.org/10.2514/3.49212.

[43] R.K. Amiet, Acoustic radiation from an airfoil in a turbulent stream, J. Sound Vib. 41 (4) (1975) 407-420, http://dx.doi.org/10.1016/S0022-460X(75) 80105-2.

[44] R.K. Amiet, High frequency thin-airfoil theory for subsonic flow, AIAA J. (ISSN: 00011452) 14 (8) (1976) 1076-1088, http://dx.doi.org/10.2514/3.7187.

[45] T. Nodé-Langlois, F. Wlassow, V. Languille, Y. Colin, B. Caruelle, J. Gill, X. Chen, X. Zhang, A.B. Parry, Prediction of contra-rotating open rotor broadband noise in isolated and installed configurations, in: 20th AIAA/CEAS Aeroacoustics Conference, 2014, http://dx.doi.org/10.2514/6.2014-2610. 